\title{
BMJ Open Study protocol for the ETMED-L project: longitudinal study of mental health and interpersonal competence of medical students in a Swiss university using a comprehensive framework of empathy
}

\author{
Alexandre Berney (D) , , Valerie Carrard (D) ,1,2 Sylvie Berney (D) ,,3 \\ Katja Schlegel (1) ," Jacques Gaume (D) ,2,5 Mehdi Gholam (D) ,6' \\ Pierre-Alexandre Bart (D) , 2,7 Martin Preisig (D) , ${ }^{2,8}$ Katarzyna Wac (D) ," \\ Marianne Schmid Mast (I) , ${ }^{10}$ Céline Bourquin (1) ${ }^{1,2}$
}

To cite: Berney A, Carrard V, Berney S, et al. Study protocol for the ETMED-L project: longitudinal study of mental health and interpersonal competence of medical students in a Swiss university using a comprehensive framework of empathy. BMJ Open 2021;11:e053070. doi:10.1136/ bmjopen-2021-053070

- Prepublication history for this paper is available online. To view these files, please visit the journal online (http://dx.doi. org/10.1136/bmjopen-2021053070).

$A B$ and $V C$ are joint first authors.

Received 04 May 2021

Accepted 22 0ctober 2021

Check for updates

(C) Author(s) (or their employer(s)) 2021. Re-use permitted under CC BY-NC. No commercial re-use. See rights and permissions. Published by BMJ.

For numbered affiliations see end of article.

Correspondence to Professor Alexandre Berney; alexandre.berney@chuv.ch

\section{ABSTRACT}

Introduction Physician interpersonal competence is crucial for patient care. How interpersonal competence develops during undergraduate medical education is thus a key issue. Literature on the topic consists predominantly of studies on empathy showing a trend of decline over the course of medical school. However, most existing studies have focused on narrow measures of empathy. The first aim of this project is to study medical students' interpersonal competence with a comprehensive framework of empathy that includes self-reported cognitive and affective empathy, performance-based assessments of emotion recognition accuracy, and a behavioural dimension of empathy. The second aim of the present project is to investigate the evolution of mental health during medical school and its putative link to the studied components of interpersonal competence. Indeed, studies documented a high prevalence of mental health issues among medical students that could potentially impact their interpersonal competence. Finally, this project will enable to test the impact of mental health and interpersonal competence on clinical skills as evaluated by experts and simulated patients.

Methods and analysis This project consists of an observational longitudinal study with an open cohort design. Each year during the four consecutive years of the project, every medical student (curriculum years 1-6) of the University of Lausanne in Switzerland will be asked to complete an online questionnaire including several interpersonal competence and mental health measures. Clinical skills assessments from examinations and training courses with simulated patients will also be included. Linear mixed models will be used to explore the longitudinal evolutions of the studied components of interpersonal competence and mental health as well as their reciprocal relationship and their link to clinical skills. Ethics and dissemination The project has received ethical approval from the competent authorities. Findings will be disseminated through internal, regional, national and international conferences, news and peer-reviewed journals.
Strengths and limitations of this study

- To tackle past research gaps, the present project investigates medical students' interpersonal competence with a comprehensive framework of empathy (cognitive and affective empathy, emotion recognition ability and behavioural adaptability) and different assessment techniques (self-reported questionnaire, performance-based test and behavioural task).

- This project is one of the first investigating the relationship between interpersonal competence, mental health and clinical skills of medical students in an open cohort design allowing both cross-sectional and longitudinal analyses.

- Data on medical students' mental health and interpersonal competence are lacking in the Swiss context and this project will compile a dataset available for comparison at the national and international level.

- Non-response and drop-out biases will be inevitable even though the financial compensation for participation should reduce them

\section{INTRODUCTION}

Physicians' interpersonal competence includes core elements of patient care such as being able to develop common therapeutic goals, sharing power and responsibility, considering the patient as a whole person, and being aware of the influence of the subjectivity and personal qualities of the physician on the practice of medicine. $^{1-3}$ The literature on the topic consists predominantly of studies on empathy and the present project thus focuses primarily on this specific component of physicians' interpersonal competence. Empathy has been shown to have a beneficial effect for both the 
patient and the physician. It is seen as an essential feature of professionalism in medicine and as one of the values of patient-centred care..$^{3-5}$ Empathy has been associated with better patient outcomes in terms of satisfaction, ${ }^{6-8}$ self-efficacy, ${ }^{7}$ enablement, ${ }^{89}$ trust,$^{6}$ anxiety, $^{8}$ distress, ${ }^{78}$ compliance, ${ }^{610}$ shared decision-making ${ }^{78}$ and even clinical outcomes. ${ }^{11}$ On the physician side, practitioners who show empathy make better clinical decisions ${ }^{12}{ }^{13}$ and receive fewer malpractice claims. ${ }^{14}$ Moreover, physicians' empathy has been shown to be related to their mental health and well-being. More empathic physicians have indeed greater professional satisfaction, ${ }^{13}$ better health, ${ }^{15}$ increased psychological well-being ${ }^{15}$ and lower burn-out incidence. ${ }^{16}$

\section{Development of interpersonal competence during medical school}

There is a long-standing and still growing body of literature on the trajectory of interpersonal competence during medical school. A study dating back to 1958 reported a tendency towards increased cynicism and decreased humanitarianism during medical school. ${ }^{17}$ Many studies focusing on empathy followed, such as the often-cited longitudinal one by Hojat et al showing a significant decline in empathy in the third year of medical school, namely when the curriculum is shifting towards clinical care activities. ${ }^{18}$ They attributed this empathy decline to several factors, such as a demanding curriculum, time pressure, environmental factors or the promotion of emotional detachment in modern medical education. Their results also suggested that there are 'at-risk medical students' more vulnerable to losing their sense of empathy. Indeed, students with lower empathy scores at the beginning of medical school (male students and those interested in technology-oriented specialties) show a steeper decrease of empathy during medical school than students with relatively higher empathy scores at the baseline. $^{18}$

While several studies confirmed such erosion of empathy in medical students, ${ }^{19-21}$ others have demonstrated no change or an increase in empathy. ${ }^{22-25}$ In this regard, a 2015 review of literature concluded that empathy does not decline over time, or at least not significantly. ${ }^{2627}$ Some also suggested that a focus on an overall trend may mask different or opposing trajectories displayed, for instance, by gender subgroups. ${ }^{4}$ Lastly, for other authors, the measures of empathy used in the existing research is also questionable. Authors indeed stressed the importance of approaching empathy as a complex socioemotional construct ${ }^{152628}$ and a review of studies using the Jefferson Scale of Physician Empathy-Student version (JSPE-S) concluded that 'more refined understandings of the nature of empathy [...]' are needed. ${ }^{27}$

\section{Towards a comprehensive framework of empathy}

Empathy is a multidimensional concept encompassing different dimensions. Two widely recognised dimensions are cognitive and affective empathy (for a review $\operatorname{se}^{29}$ ).
Cognitive empathy refers to the correct understanding of another person's feelings (emotion recognition) and perspective (perspective taking). Affective or emotional empathy refers to the experience of prosocial and sympathetic feelings towards another person in distress (empathic concern) ${ }^{30}$ or feeling the same emotion as another person (emotion contagion). ${ }^{31}$

As acknowledged by several authors, a comprehensive understanding of empathy should include the ability to understand others (cognitive empathy) and to share others' feelings (affective empathy), but also the provision of a communicative response that conveys this understanding and sharing of another's perspective and emotions. ${ }^{32}$ This empathic communicative response can be provided through behavioural adaptability, which is the ability to adjust one's interaction style to the individual needs, desires and preferences of an interactional partner. ${ }^{33}{ }^{34}$ In the clinical context, this implies that there is not one physician interaction style that is the best, but that physicians should adapt to each specific situation based on an empathic understanding of the patient ${ }^{33} 3536$ and studies confirmed that this physician's behavioural adaptability is indeed related to higher patient satisfaction and trust in the physician. ${ }^{36} 37$

So far, research on empathy change over the course of medical school mostly relied on self-report measures of cognitive empathy. However, one can also rely on performance task-based tests to measure the ability to understand others. Indeed, several tests assessing emotion recognition ability (ERA) have been developed and validated. ${ }^{38}$ These ERA tests consist of pictures or short videos of individuals portraying an emotion through facial, vocal and bodily expressions. Individuals' ERA is then measured as the number of emotions correctly recognised. Empirical research supports that ERA is an important interpersonal competence for clinicians. ${ }^{39}$ Practitioners with high ERA scores show more patientcentred behaviours, ${ }^{4041}$ make more accurate diagnoses ${ }^{42}$ and have less distressed, ${ }^{41}$ more satisfied, ${ }^{43}$ and more compliant patients. ${ }^{44}$

To the best of our knowledge, Smith et $a l^{28}$ were the only ones adding performance task-based measures (emotion recognition task and facial expression sensitivity test) to the generally used self-reported questionnaires of empathy. Their results replicated the decline usually observed in the JSPE-S scores, but the scores of the Questionnaire of Cognitive and Affective Empathy (QCAE) and performance task-based tests showed an increase over time. ${ }^{28}$ This indicates that different dimensions of medical students' empathy might evolve differently during medical school. Smith et al's study was limited to the first 3 years of medical school and did not investigate empathic communicative responses of medical students. Thus, more longitudinal studies including a behavioural dimension of empathy such as behavioural adaptability are needed to achieve a more comprehensive understanding of the evolution of empathy during medical school. Moreover, there is 
a lack of research on the potential impact of students' interpersonal competence on their mental health and clinical skills.

\section{Mental health of medical students}

A 2016 meta-analysis ${ }^{45}$ estimated a prevalence of $27.2 \%$ for depression and $11.1 \%$ for suicidal ideation among medical students. Furthermore, the prevalence of burn-out and other forms of distress in medical students, residents/fellows and early career physicians was shown to be much higher compared with similarly aged college graduates pursuing other careers. ${ }^{46} \mathrm{~A}$ few longitudinal studies explored mental health problems, ${ }^{47}$ burn-out and suicidal ideation, ${ }^{48} 49$ depression, ${ }^{50}{ }^{51}$ or life satisfaction in medical students, ${ }^{52}{ }^{53}$ but none has concurrently investigated the longitudinal evolution of both interpersonal competence and mental health of medical students. Cross-sectional studies provide evidence that more empathic physicians have greater professional satisfaction, ${ }^{13}$ higher well-being ${ }^{15}$ and lower burn-out incidence. ${ }^{16}$ The link between empathy and mental health might even be bidirectional as studies showed that medical students' mental health and wellbeing impact their empathy ${ }^{54}$ with stress being related to burn-out and, in turn, to a deterioration of empathy towards patients. ${ }^{55}$ Thus, longitudinal exploration of the relationship between medical students' interpersonal competence and mental health is needed to understand how and when one influences the other.

\section{Aims}

This project aims to explore the longitudinal evolution of interpersonal competence and mental health during medical school. To tackle past research gaps, interpersonal competence will be investigated with a comprehensive framework of empathy (cognitive and affective empathy, ERA and behavioural adaptability) and different assessment techniques (self-reported questionnaire, performance-based test and behavioural task). We will also investigate several indicators of mental health, which may be related to the medical students' empathy. Additionally, we will explore how the studied components of interpersonal competence and mental health can predict clinical skills evaluated during examinations or training courses with simulated patients. Four primary research questions will thus be addressed:

RQ1. How differently do cognitive and affective empathy, ERA and behavioural adaptability evolve over the course of medical school?

RQ2. How does mental health evolve over the course of medical school?

RQ3. How do the studied components of interpersonal competence (see RQ1) and mental health relate to each other?

RQ4. How do the studied components of interpersonal competence (see RQ1) and mental health relate to clinical skills?

\section{METHODS AND ANALYSIS}

\section{Design and population}

This project consist of a 4-year observational study with an open cohort design, which will allow for both crosssectional and longitudinal analyses. Each year, every medical student in the curriculum years 1-6 at the University of Lausanne (Switzerland) will be eligible for participation, except foreign students who are in the university as part of an academic exchange for one or two semesters. The eligible population size is estimated to be 1500 each year.

\section{Procedure}

During the 4years of the project (2020-2024), four waves of online questionnaires will be administered during an exam-free month. At each wave, in the beginning of the data collection month, eligible students will be invited by email to fill in an online questionnaire. Data collection will be open for 30 days and two electronic reminders will be sent during this period. Participants will receive a financial compensation of CHF50 ( $\sim \mathrm{US} \$ 50)$ for each online questionnaire completion. Financial compensation likely increases the overall response rate and was deemed fair for the effort and time students take for the study. However, individuals could then participate solely for monetary benefits and be less attentive when filling in the questionnaire. To tackle this issue, two attention questions will be introduced in the questionnaire (eg, 'In order to check your attention, please answer 'Slightly agree' to this question.') and participants giving wrong answers to any of these attention questions will be excluded from the analysis.

On top of the online questionnaire, clinical skills ratings will be included. The ratings collected for each student providing specific informed consent for this in the online questionnaire will be the Objective Structured Clinical Examination (OSCE) scores and coding by simulated patients when students practice their clinical skills during specific training courses.

Data will be coded to protect confidentiality. All participants will be assigned an identification code, which will be used throughout the project. A secured correspondence table between participant's codes and participant's personal data will be kept separately from the datasets.

\section{Measures}

Besides sociodemographic, medical studies and health related information, three categories of measures will be collected: interpersonal competence, mental health and clinical skills (see table 1 for a complete list of instruments, sample items and scales). The choice of instruments was based on previous research in the field, psychometric qualities and comparability to existing cross-sectional or cohort studies.

Sociodemographic, medical studies and health related information The participants' sociodemographic, medical studies and health related information collected through the 
Table 1 Measures

\begin{tabular}{|c|c|c|c|c|}
\hline & Variables & Instruments & No of items & Sample item (scale) \\
\hline \multirow[t]{3}{*}{$\begin{array}{l}\text { Interpersonal } \\
\text { competence }\end{array}$} & Cognitive empathy & $\begin{array}{l}\text { Jefferson Scale of } \\
\text { Physician Empathy- } \\
\text { Student version }\end{array}$ & 20 & $\begin{array}{l}\text { 'Patients feel better when their physicians } \\
\text { understand their feelings.' ( } 1=\text { strongly } \\
\text { disagree; } 7=\text { strongly agree) }\end{array}$ \\
\hline & $\begin{array}{l}\text { Cognitive and affective } \\
\text { empathy }\end{array}$ & $\begin{array}{l}\text { Questionnaire of } \\
\text { Cognitive and Affective } \\
\text { Empathy }\end{array}$ & 31 & $\begin{array}{l}\text { 'I am good at predicting how someone } \\
\text { will feel.' ( } 1=\text { strongly disagree; } 2=\text { slightly } \\
\text { disagree; } 3=\text { =slightly agree; } 4=\text { strongly agree) }\end{array}$ \\
\hline & Behavioural adaptability & $\begin{array}{l}\text { The Ability to Modify } \\
\text { Self-Presentation Scale }\end{array}$ & 7 & $\begin{array}{l}\text { 'When I feel that the image I am portraying } \\
\text { isn't working, I can readily change it to } \\
\text { something that does.' }(0=\text { strongly disagree; } \\
1=\text { disagree; } 2=\text { slightly disagree; } 3=\text { slightly } \\
\text { agree; } 4=\text { agree; } 5=\text { strongly agree) }\end{array}$ \\
\hline \multirow{7}{*}{$\begin{array}{l}\text { Mental } \\
\text { health }\end{array}$} & Suicidal ideation & $\begin{array}{l}\text { Two questions of the } \\
\text { Beck Depression } \\
\text { Inventory }\end{array}$ & 2 & $\begin{array}{l}\text { 'How did you feel during the past } 2 \text { weeks?' } \\
(0=\text { I don't have any thoughts of killing } \\
\text { myself; } 1=\text { I have thoughts of killing myself, } \\
\text { but I would not carry them out; } 2=\text { I would } \\
\text { like to kill myself; } 3=\text { I would kill myself if I } \\
\text { had the chance) }\end{array}$ \\
\hline & Anxiety & $\begin{array}{l}\text { Trait subscale of the } \\
\text { State-Trait Anxiety } \\
\text { Inventory }\end{array}$ & 20 & $\begin{array}{l}\text { 'I feel nervous and restless.' ( } 1=\text { no; } \\
2=\text { ratherno; } 3=\text { ratheryes; } 4=\text { yes) }\end{array}$ \\
\hline & Stress sources & Sources of stress items & 6 & $\begin{array}{l}\text { 'Indicate to which extent each of the } \\
\text { followingt was a source of stress in your life } \\
\text { during the last } 12 \text { months on a scale from } 1 \\
\text { 'none' to } 10 \text { 'extreme'?' }\end{array}$ \\
\hline & Burn-out & $\begin{array}{l}\text { Maslach Burn-out } \\
\text { Inventory Student-Survey }\end{array}$ & 15 & $\begin{array}{l}\text { 'I feel emotionally drained by my studies.' } \\
\text { ( } 1=\text { =never; } 2=\text { rarely; } 3=\text { sometimes, } 4=\text { often, } \\
5=\text { very often, } 6=\text { always) }\end{array}$ \\
\hline & Coping strategies & $\begin{array}{l}\text { Coping section of the } \\
\text { Euronet questionnaire }\end{array}$ & 17 & $\begin{array}{l}\text { 'I try to calm down.' }(0=\text { not at all common } \\
\text { for me; } 1=\text { not very common for me; } 2=\text { quite } \\
\text { common for me; } 3=\text { very common for me) }\end{array}$ \\
\hline & $\begin{array}{l}\text { Psychoactive substance } \\
\text { use }\end{array}$ & $\begin{array}{l}\text { Alcohol, Smoking and } \\
\text { Substance Involvement } \\
\text { Screening Test }\end{array}$ & 10-64‡ & $\begin{array}{l}\text { 'In your life, which of the following } \\
\text { substances have you ever used? (non- } \\
\text { medical use only)' ( } 0=\text { no; } 3=y e s)\end{array}$ \\
\hline & $\begin{array}{l}\text { Neuroenhancement } \\
\text { drugs use }\end{array}$ & $\begin{array}{l}\text { Cohort Study on } \\
\text { Substance Use Risk } \\
\text { Factors questionnaire of } \\
\text { neuroenhancement drugs } \\
\text { use }\end{array}$ & 20 & $\begin{array}{l}\text { 'How often did you use Neuroenhancement } \\
\text { drugs over the past } 12 \text { months?' }(0=\text { never; } \\
1=\text { once; } 2=2 \text { to } 3 \text { times a year; } 3=4-9 \text { times } \\
\text { a year; } 4=1-2 \text { times a month; } 5=3-4 \text { times } \\
\text { a month; } 6=2-3 \text { times a week, } 7=4 \text { times a } \\
\text { week or more) }\end{array}$ \\
\hline
\end{tabular}


Table 1 Continued

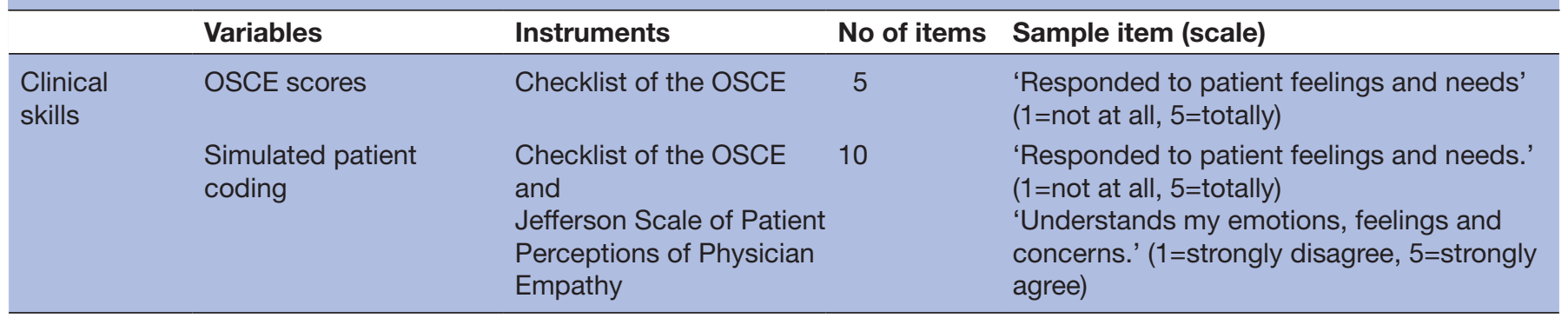

*Pride, joy, amusement, pleasure, relief, interest, surprise, anxiety, fear, despair, sadness, disgust, irritation and anger.

†Family, financial situation, paid activity, sentimental life, studies and work/life balance.

$\ddagger$ Across nine substances: tobacco, alcohol, cannabis, cocaine, amphetamine, inhalants, sedatives, hallucinogens and opioids; with follow-up questions for the substances reported to be used.

OSCE, Objective Structured Clinical Examination.

yearly online questionnaire will include age, gender, native language, level of education of parents, relationship status, living arrangements, hours spend in paid job, financial resources, education before medical studies, hours spent on medical studies per week, drop-out thoughts, medical specialisation targeted, professional identity, ${ }^{56}$ experience of sexism or sexual harassment, health satisfaction, ${ }^{57}$ hours of physical activity per week, weight, height, hours of sleep, satisfaction with sleep and psychiatric/psychotherapeutic past consultation.

\section{Interpersonal competence}

Regarding interpersonal competence, medical students' empathy in terms of cognitive and affective empathy, ERA, and behavioural adaptability will be measured through the yearly questionnaire.

Cognitive and affective empathy will be measured with two often used self-reported instruments: the JSPE-S and the QCAE. The JSPE-S was developed to assess medical students' orientations or attitudes towards empathic relationships in the context of patient care $^{58}$ and was thus meant to measure the cognitive dimension of empathy. It is maybe the most researched and widely used empathy instrument in medical education ${ }^{59}$ and it benefits from solid psychometric foundations. ${ }^{27} \mathrm{~A} 4$-year licence will be purchased for the use of the JSPE-S.

The QCAE was validated in a large sample of university students and both the English and the French version have been shown to reliably assess the two main dimensions of empathy (cognitive and affective) and five correlated subdimensions (perspective taking, online simulation, emotion contagion, peripheral responsivity and proximal responsivity). ${ }^{6061}$

ERA will be assessed with a performance-based test: The Geneva Emotion Recognition Test short version (GERT-S) ${ }^{62}$ The test consists of 42 short videos (about $3 \mathrm{~s}$ each) of actors portraying one out of 14 different emotions (eg, fear, despair, surprise, disgust, anger). The ERA score is then computed as the percent of correctly recognised portrayals. The GERT-S is a multimodal and dynamic ERA test as the actors express emotions through their face, body, and voice. A recent meta-analysis showed that the GERT-S has the highest average reliability among interpersonal accuracy tests and yields the highest average correlation with other ERA tests. ${ }^{38}$ Several studies also support the construct and predictive validity of this test. $^{3863}$

Behavioural adaptability will be assessed with the Ability to Modify Self-Presentation Scale (AMSP). The AMSP is a dimension of self-monitoring (ie, the extent to which people regulate and control their self-presentation) measured in the Lennox and Wolfe revised selfmonitoring scale. This scale shows better psychometric and construct validity than the original version proposed by Snyder ${ }^{64}$ and several factorial analyses confirmed the general structure of the scale ${ }^{6566}$ including two dimensions: the Sensitivity to Expressive Behaviour of Other and the AMSP. The AMSP assesses one's ability to adapt expressive behaviours in different social situations ${ }^{64}$ and was thus chosen as a self-reported measure of behavioural adaptability. The validated French version of the AMSP, which showed good internal consistency and test-retest reliability in a sample of French students,${ }^{67}$ will be used in the present project.

In addition to the self-reported AMSP, we will develop a behavioural adaptability task-based assessment that will be proposed to a subsample of volunteer medical students. The goal will be to measure actual displays of behavioural adaptability by coding the extent to which participants adapt their interaction styles to different interactional partners or situations. This has been done in a past study conducted by one of the present project's coinvestigators in which participants performed a task with two interactional partners having different needs and preferences. ${ }^{68}$

\section{Mental health}

Depressive symptoms, suicidal ideation, anxiety, stress, burn-out, coping strategies and psychoactive substance use will be investigated in the yearly online questionnaire. Importantly, the choice of instruments will allow a comparison with data of a previous cross-sectional study of Lausanne medical students' mental health (2018 unpublished Master thesis by Mayor, B: Mental health of the Lausanne medical students) as well as with the general 
population, taking advantage from a large populationbased study ongoing in the city of Lausanne over the past 15 years (CoLauslPsyCoLaus). ${ }^{69}$ The cohort of offspring of the CoLaus/PsyCoLaus participants is indeed in the same age range as the students of the present project.

Depressive symptoms will be assessed with the Centre for Epidemiological Studies-Depression (CES-D). Participants rate how often over the past week they experienced symptoms associated with depression. ${ }^{70}$ The validated French version of the CES-D showed good internal consistency as well as adequate structural and construct validity ${ }^{71}$ It also provides cut-off scores with good sensitivity and specificity. ${ }^{71}$

Suicidal ideation will be evaluated using 2 questions of the Beck Depression Inventory (BDI).$^{72} 73$ The BDI is well validated and has been shown to accurately distinguish individuals at risk of suicidal attempts (based on past and present suicidal behaviour) from other individuals. ${ }^{74}$ In the present project, the validated French version of two items belonging to the same higher construct of 'Negative attitude' will be used. ${ }^{75}$

Anxiety will be assessed with the trait subscale of the State-Trait Anxiety Inventory (STAI), which measures the level of anxiety participants 'generally feel' ${ }^{76}$ Considerable evidence attests to the construct and concurrent validity of the scale. ${ }^{77}$ Studies also have shown that it is a sensitive predictor of caregiver distress over time, and that it can vary with changes in support systems, health and other individual characteristics. ${ }^{7879}$

Furthermore, we created an adaptation of the STAI measuring the level of anxiety 'during this COVID-19 pandemic' that will be added to the questionnaire because the first data collection wave will take place during the pandemic (March 2021).

Stress will be measured with one item assessing the general level of stress and six items assessing stress sources (family life, financial situation, paid activity, sentimental life, studies and work/life balance). These items were used in a previous cross-sectional study of Lausanne medical students (2018 unpublished Master thesis by Mayor, B: Mental health of the Lausanne medical students) and integrated to the questionnaire for comparability purpose.

Burn-out will be measured with the Maslach Burn-out Inventory Student-Survey (MBI-SS). This scale designed to measure the burn-out level of students evaluates the dimensions of Emotional Exhaustion (five items), Cynicism (four items) and Academic Efficacy (six items, reversed dimension). A French version of the MBI-SS was validated and indicated good internal consistency and adequate structural validity. ${ }^{80}$

Coping strategies will be assessed using the French version of the coping section of the Euronet questionnaire validated in a random community sample in Lausanne. ${ }^{81}$ Confirmatory factor analysis supported a three-dimension structure with Emotion-focused coping (nine items), Help-seeking (four items) and Problemfocused coping (four items).
Psychoactive substance use will be measured using the WHO's Alcohol, Smoking and Substance Involvement Screening Test ${ }^{82}$ and the Cohort Study on Substance Use Risk Factors questionnaire of neuroenhancement drugs use. $^{83}$

\section{Clinical skills}

At the University of Lausanne, OSCE are carried out to assess medical students' clinical skills at the end of the third, fifth and sixth curriculum year. OSCE stations represent clinical situations in which students interact with simulated patients. In some stations, experts systematically assess communication skills using a five-item checklist (see table 1 for sample items). These scores will be retrieved for the students giving formal consent to share this data.

Moreover, communication training courses with simulated patients are conducted from the second to the fifth curriculum year on different topics (eg, history taking, breaking bad news ${ }^{84-86}$ and motivational interview ${ }^{87}$ ). As part of this project, simulated patients will be asked to fill in a grid at the end of the interviews with students that includes the OSCE communication five-item checklist as well as the Jefferson Scale of Patient Perceptions of Physician Empathy ${ }^{88}$ (see table 1 for sample items).

\section{Data analysis}

Due to the longitudinal nature of the project, linear mixed models (LMMs) will be used to describe the evolution of continuous variables during the course of medical school, adjusting for sociodemographic variables and potential covariates. ${ }^{89}$ LMMs combine fixed-effects and random effects in the same model simultaneously. The fixed effects part combines the effect of fixed variables (in this case age, gender, etc) on the response. The random part, on the other hand, allows adjusting the model for interdependence among observations (eg, repeated measures from the same individuals are likely to be correlated; measures from students of the same curriculum year are likely to be correlated). To model the longitudinal evolution of dichotomous variables, generalised LMMs (GLMMs) which are generalised counterparts of LMMs will be used. In the GLMMs, predictors are related to the outcome using a link function (usually the logit link function, as in the logistic regression) with a random part allowing the analysis of inter-correlated observations. There are several approaches available to fit GLMMs; penalised quasi-likelihood will be used to approximate and maximise the likelihood for GLMMs, which provides certain optimality characteristics for estimated parameters. ${ }^{90}$

Apart from adjusting the models for potential covariates, current and lagged observations of mental health variables (from previous time points) can also be included to study the effect of current and previous mental health status on the studied components of interpersonal competence and vice-versa. The same will be done to assess the potential influence of interpersonal 
dimensions and mental health on clinical skills. Ordinary dimension-reduction techniques such as model selection (based on Akaike information criterion, etc) will be used to ensure that models present an acceptable goodness of fit and avoid overadjustment in the models.

Every student who gave consent for participation will be considered for analysis. Students who respond at least on two waves of questionnaires will be included in the longitudinal analyses. The advantage of using LMMs and GLMMs is that cases with missing data will still contribute to the models with all their other observed data (eg, a participant having missed one wave of annual assessment will contribute all the other measured waves). Multivariate imputation by chained equations will also be used to remedy the presence of potential missing values, in order to reduce the potential bias. ${ }^{91}$

\section{Sample size calculation}

Apart from the curriculum year 1, which brings together more than 750 medical students, there is an average of 240 medical students per curriculum year in the University of Lausanne Medical School, which means more than 1500 eligible participants each year. Past studies with medical students report yearly response rates varying from $32 \%$ to $91 \% 4284849515292-96$ and response rates across several years from $20 \%$ to $74 \% .{ }^{474515292}$ Given the participation compensation, we expect to achieve a response rate of $35 \%$. We used the Monte Carlo method to estimate the potential statistical power of the LMMs to detect a small change in individuals' response from 1 year to the other (as small as $1 \%$ change per year, which is a very conservative projection). Even in a pessimistic situation where participation rate is just $25 \%$ and large error variance in responses, we can still expect a $77 \%$ power in detecting the effect size as small as $1 \%$ change per year. We have even higher power in detecting the effect of a potential covariate (over 93\%) on the response.

\section{Patient and public involvement}

This project and its research questions are very much driven by a growing interest and worry regarding young adults' mental health. The online questionnaire was pretested by medical students to evaluate the burden of the participation and medical students' delegates were involved in the advertisement of the project. Moreover, an online newsfeed will be available to inform on the project's progress.

The representative of the medical school of the University of Lausanne and the contact person for issues related to mental health among students at Lausanne medical school are both coinvestigators of the present project. Exchanges regarding medical students' needs and medical education strategies are thus ongoing since the beginning of the project drafting and will continue even after the completion of the project. Indeed, this collaboration will enable to translate the clinical implications of the project into educational strategies to implement in our university.

\section{RELEVANCE AND IMPACT}

The data collected through the ETMED-L project will be key to a better understanding of the longitudinal development of interpersonal competence and mental health as well as their reciprocal influence over the course of medical studies. By adopting a more comprehensive framework of empathy including different dimensions (cognitive and affective empathy, ability to recognise emotions and a behavioural counterpart of empathy) and using different measurement methods (self-report and performance-based tests) this project will contribute to fill an important gap in the literature. It will allow a better understanding of the differential evolution of specific dimensions of empathy and will help to improve the curriculum of medical studies, particularly in relation to potential critical periods.

There are preliminary data indicating that medical students are at risk of mental health problems and that it may impact their ability to interact with patients, which ultimately may impair their ability to practice medicine. On top of mental health problems, tendency to distancing and loss of empathy have consistently been reported in residents and physicians, highlighting the importance of addressing these issues already during medical studies. This project will contribute to current efforts to understand and promote mental health of students in medical schools. Moreover, dimensions that are usually approached separately-interpersonal competence and mental health-will be analysed concurrently, which makes this project unique. Having a better understanding of the longitudinal course of mental health in relation to interpersonal competence will help to develop prevention strategies and to provide better support and supervision.

\section{Ethics and dissemination}

The project was approved by the Human Research Ethics Committee of the Canton de Vaud (protocol number 2020-02474). The participation poses little to no risk to the participants. However, as the questionnaire includes mental health questions, we will clearly indicate that students experiencing distress can refer to the psychiatric emergency ward of Lausanne University Hospital or contact the psychotherapeutic consultation for students of the University of Lausanne, which offers prompt on-site consultations.

Findings will be disseminated through internal, regional, national, and international conferences, news and peer-reviewed journals.

\section{Author affiliations}

${ }^{1}$ Psychiatric Liaison Service, Lausanne University Hospital, Lausanne, Switzerland

${ }^{2}$ Faculty of Biology and Medicine, University of Lausanne, Lausanne, Switzerland

${ }^{3}$ Service of General Psychiatry, Lausanne University Hospital, Lausanne, Switzerland

${ }^{4}$ Institute of Psychology, University of Bern, Bern, Switzerland

${ }^{5}$ Alcohol Treatment Centre, Lausanne University Hospital, Lausanne, Switzerland

${ }^{6}$ Institute of Mathematics, EPFL, Lausanne, Switzerland

${ }^{7}$ Department of Internal Medicine, Lausanne University Hospital, Lausanne,

Switzerland 
${ }^{8}$ Centre for Psychiatric Epidemiology and Psychopathology, Lausanne University Hospital, Lausanne, Switzerland

${ }^{9}$ Department of Computer Science, University of Geneva, Geneva, Switzerland

${ }^{10}$ Department of Organizational Behavior, University of Lausanne, Lausanne,

Switzerland

Contributors $A B, C B$ and MSM designed the project with input from all other authors. VC, $A B$ and $C B$ drafted the present manuscript. SB, KS, JG, MG, P-AB, MP and $\mathrm{KW}$ contributed to the establishment and refinement of project procedures and critically revised the manuscript. All authors approved the final version of the manuscript.

Funding This work is supported by the Swiss National Science Foundation (grant number 10001C_197442).

Competing interests None declared.

Patient and public involvement Patients and/or the public were involved in the design, or conduct, or reporting, or dissemination plans of this research. Refer to the Methods section for further details.

Patient consent for publication Not applicable.

Provenance and peer review Not commissioned; externally peer reviewed.

Open access This is an open access article distributed in accordance with the Creative Commons Attribution Non Commercial (CC BY-NC 4.0) license, which permits others to distribute, remix, adapt, build upon this work non-commercially, and license their derivative works on different terms, provided the original work is properly cited, appropriate credit is given, any changes made indicated, and the use is non-commercial. See: http://creativecommons.org/licenses/by-nc/4.0/.

\section{ORCID iDs}

Alexandre Berney http://orcid.org/0000-0001-9535-1222

Valerie Carrard http://orcid.org/0000-0001-7355-9567

Sylvie Berney http://orcid.org/0000-0001-7099-6999

Katja Schlegel http://orcid.org/0000-0003-3768-5544

Jacques Gaume http://orcid.org/0000-0002-9149-0994

Mehdi Gholam http://orcid.org/0000-0002-1523-9300

Pierre-Alexandre Bart http://orcid.org/0000-0001-7685-8968

Martin Preisig http://orcid.org/0000-0001-5689-4259

Katarzyna Wac http://orcid.org/0000-0002-8060-399X

Marianne Schmid Mast http://orcid.org/0000-0001-5510-610X

Céline Bourquin http://orcid.org/0000-0001-9584-2929

\section{REFERENCES}

1 Duffy FD, Gordon GH, Whelan G, et al. Assessing competence in communication and interpersonal skills: the Kalamazoo II report. Acad Med 2004;79:495-507.

2 Dohrenwend AM. Defining empathy to better teach, measure, and understand its impact. Acad Med 2018;93:1754-6.

3 Mead N, Bower P. Patient-centredness: a conceptual framework and review of the empirical literature. Soc Sci Med 2000;51:1087-110.

4 Quince TA, Parker RA, Wood DF, et al. Stability of empathy among undergraduate medical students: a longitudinal study at one UK medical school. BMC Med Educ 2011;11:90-8.

5 Crandall SJ, Marion GS. Commentary: identifying attitudes towards empathy: an essential feature of professionalism. Acad Med 2009;84:1174-6.

6 Kim SS, Kaplowitz S, Johnston MV. The effects of physician empathy on patient satisfaction and compliance. Eval Health Prof 2004;27:237-51.

7 Zachariae R, Pedersen CG, Jensen AB, et al. Association of perceived physician communication style with patient satisfaction, distress, cancer-related self-efficacy, and perceived control over the disease. Br J Cancer 2003;88:658-65.

8 Derksen F, Bensing J, Lagro-Janssen A. Effectiveness of empathy in general practice: a systematic review. Br J Gen Pract 2013;63:e76-84.

9 Mercer SW, Neumann M, Wirtz M, et al. General practitioner empathy, patient enablement, and patient-reported outcomes in primary care in an area of high socio-economic deprivation in Scotland--a pilot prospective study using structural equation modeling. Patient Educ Couns 2008;73:240-5.

10 Vermeire E, Hearnshaw H, Van Royen P, et al. Patient adherence to treatment: three decades of research. A comprehensive review. J Clin Pharm Ther 2001;26:331-42.
11 Hojat M, Louis DZ, Markham FW, et al. Physicians' empathy and clinical outcomes for diabetic patients. Acad Med 2011;86:359-64.

12 Larson EB, Yao X. Clinical empathy as emotional labor in the patientphysician relationship. JAMA 2005;293:1100-6.

13 Gleichgerrcht E, Decety J. The relationship between different facets of empathy, pain perception and compassion fatigue among physicians. Front Behav Neurosci 2014;8:1-9.

14 Hickson GB, Federspiel CF, Pichert JW. Patient complaints and malpractice risk. JAMA 2002;287:2951-7.

15 Halpern J. What is clinical empathy? J Gen Intern Med 2003;18:670-4.

16 Brazeau CMLR, Schroeder R, Rovi S, et al. Relationships between medical student burnout, empathy, and professionalism climate. Acad Med 2010;85:S33-6.

17 Eron LD. The effect of medical education on attitudes: a follow-up study. J Med Educ 1958;33:25-33.

18 Hojat M, Vergare MJ, Maxwell K, et al. The devil is in the third year: a longitudinal study of erosion of empathy in medical school. Acad Med 2009;84:1182-91.

19 Austin EJ, Evans P, Magnus B, et al. A preliminary study of empathy, emotional intelligence and examination performance in $\mathrm{MBChB}$ students. Med Educ 2007:41:684-9.

20 Chen D, Lew R, Hershman W, et al. A cross-sectional measurement of medical student empathy. J Gen Intern Med 2007;22:1434-8.

21 Youssef FF, Nunes P, Sa B, et al. An exploration of changes in cognitive and emotional empathy among medical students in the Caribbean. Int J Med Educ 2014;5:185-92.

22 Tavakol S, Dennick R, Tavakol M. Empathy in UK medical students: differences by gender, medical year and specialty interest. Educ Prim Care 2011;22:297-303.

23 Paro HBMS, Silveira PSP, Perotta B, et al. Empathy among medical students: is there a relation with quality of life and burnout? PLOS One 2014:9:e94133.

24 Toto RL, Man L, Blatt B, et al. Do empathy, perspective-taking, sense of power and personality differ across undergraduate education and are they inter-related? Adv Health Sci Educ Theory Pract 2015;20:23-31.

25 Bratek A, Bulska W, Bonk M, et al. Empathy among physicians, medical students and candidates. Psychiatr Danub 2015;27(Suppl 1):S48-52.

26 Quince T, Thiemann P, Benson J, et al. Undergraduate medical students' empathy: current perspectives. Adv Med Educ Pract 2016;7:443-55.

27 Roff S. Reconsidering the "decline" of medical student empathy as reported in studies using the Jefferson Scale of Physician EmpathyStudent version (JSPE-S). Med Teach 2015;37:783-6.

28 Smith KE, Norman GJ, Decety J. The complexity of empathy during medical school training: evidence for positive changes. Med Educ 2017;51:1146-59.

29 Cuff BMP, Brown SJ, Taylor L, et al. Empathy: a review of the concept. Emot Rev 2016;8:144-53.

30 Davis MH. Measuring individual differences in empathy: evidence for a multidimensional approach. J Pers Soc Psychol 1983:44:113-26.

31 Hatfield E, Cacioppo JT, Rapson RL. Emotional contagion. New York, NY: Cambridge University Press, 1994

32 Mercer SW, Reynolds WJ. Empathy and quality of care. Br J Gen Pract 2002;52(Suppl):S9-12.

33 Carrard V, Schmid Mast M. Physician behavioral adaptability: A model to outstrip a "one size fits all" approach. Patient Educ Couns 2015;98:1243-7.

34 Carrard V. Non-verbal adaptation to the interlocutors' inner characteristics: relevance, challenges, and future directions. Front Psychol 2021;12:612664.

35 Epstein R, Street RL. Patient-centered communication in cancer care: promoting healing and reducing suffering. Bethesda, MD: National Cancer Institute, 2007.

36 Carrard V, Schmid Mast M, Cousin G. Beyond "one size fits all": Physician nonverbal adaptability to patients' need for paternalism and its positive consultation outcomes. Health Commun 2016;31:1327-33.

37 Carrard V, Schmid Mast M, Jaunin-Stalder N, et al. Patientcenteredness as physician behavioral adaptability to patient preferences. Health Commun 2018;33:593-600.

38 Schlegel K, Boone RT, Hall JA. Individual differences in interpersonal accuracy: a multi-level meta-analysis to assess whether judging other people is one skill or many. J Nonverbal Behav 2017:41:103-37.

39 Hall JA. Clinicians' accuracy in perceiving patients: its relevance for clinical practice and a narrative review of methods and correlates. Patient Educ Couns 2011;84:319-24. 
40 Hall JA, Ship AN, Ruben MA, et al. Clinically relevant correlates of accurate perception of patients' thoughts and feelings. Health Commun 2015;30:423-9.

41 Hall JA, Roter DL, Blanch DC, et al. Nonverbal sensitivity in medical students: implications for clinical interactions. J Gen Intern Med 2009;24:1217-22.

42 Robbins JM, Kirmayer LJ, Cathébras P, et al. Physician characteristics and the recognition of depression and anxiety in primary care. Med Care 1994;32:795-812.

43 DiMatteo MR, Taranta A, Friedman HS, et al. Predicting patient satisfaction from physicians' nonverbal communication skills. Med Care 1980;18:376-87.

44 DiMatteo MR, Hays RD, Prince LM. Relationship of physicians' nonverbal communication skill to patient satisfaction, appointment noncompliance, and physician workload. Health Psychol 1986;5:581-94.

45 Rotenstein LS, Ramos MA, Torre M, et al. Prevalence of depression, depressive symptoms, and suicidal ideation among medical students: a systematic review and meta-analysis. JAMA 2016;316:2214-36.

46 Dyrbye LN, West CP, Satele D, et al. Burnout among U.S. medical students, residents, and early career physicians relative to the general U.S. population. Acad Med 2014;89:443-51.

47 Borst JM, Frings-Dresen MHW, Sluiter JK. Prevalence and incidence of mental health problems among Dutch medical students and the study-related and personal risk factors: a longitudinal study. Int $J$ Adolesc Med Health 2015;28:349-55.

48 Dyrbye LN, Thomas MR, Massie FS, et al. Burnout and suicidal ideation among U.S. medical students. Ann Intern Med 2008;149:334-41.

49 Guthrie E, Black D, Bagalkote H, et al. Psychological stress and burnout in medical students: a five-year prospective longitudinal study. J R Soc Med 1998;91:237-43.

50 Quince TA, Wood DF, Parker RA, et al. Prevalence and persistence of depression among undergraduate medical students: a longitudinal study at one UK medical school. BMJ Open 2012;2:e001519.

51 Silva V, Costa P, Pereira I, et al. Depression in medical students: insights from a longitudinal study. BMC Med Educ 2017;17:184-92.

52 Kjeldstadli K, Tyssen R, Finset A, et al. Life satisfaction and resilience in medical school--a six-year longitudinal, nationwide and comparative study. BMC Med Educ 2006;6:48-55.

53 Sandover S, Jonas-Dwyer D, Marr T. Graduate entry and undergraduate medical students' study approaches, stress levels and ways of coping: a five year longitudinal study. BMC Med Educ 2015;15:5-15.

54 Thomas MR, Dyrbye LN, Huntington JL, et al. How do distress and well-being relate to medical student empathy? A multicenter study. $J$ Gen Intern Med 2007;22:177-83.

55 Passalacqua SA, Segrin C. The effect of resident physician stress, burnout, and empathy on patient-centered communication during the long-call shift. Health Commun 2012;27:449-56.

56 Adams K, Hean S, Sturgis P, et al. Investigating the factors influencing professional identity of first-year health and social care students. Learn Health Soc Care 2006;5:55-68.

57 World Health Organization. Division of Mental Health. WHOQOLBREF : introduction, administration, scoring and generic version of the assessment : field trial version, 1996. Available: https://apps.who. int/iris/handle/10665/63529 [Accessed 22 Sep 2021].

58 Hojat M, Mangione S, Nasca TJ, et al. The Jefferson scale of physician empathy: development and preliminary psychometric data. Educ Psychol Meas 2001;61:349-65.

59 Colliver JA, Conlee MJ, Verhulst SJ. Letter to the editor. Acad Med 2010;85:1813-4.

60 Reniers RLEP, Corcoran R, Drake R, et al. The QCAE: a questionnaire of cognitive and affective empathy. J Pers Assess 2011;93:84-95.

61 Myszkowski N, Brunet-Gouet E, Roux P, et al. Is the questionnaire of cognitive and affective empathy measuring two or five dimensions? evidence in a French sample. Psychiatry Res 2017;255:292-6.

62 Schlegel K, Grandjean D, Scherer KR. Introducing the Geneva emotion recognition test: an example of Rasch-based test development. Psychol Assess 2014;26:666-72.

63 Schlegel K, Palese T, Mast MS, et al. A meta-analysis of the relationship between emotion recognition ability and intelligence. Cogn Emot 2020;34:329-51.

64 Lennox RD, Wolfe RN. Revision of the self-monitoring scale. J Pers Soc Psychol 1984;46:1349-64.

65 O'Cass A. A psychometric evaluation of a revised version of the Lennox and Wolfe revised self-monitoring scale. Psychol Mark 2000;17:397-419.
66 Cramer KM, Gruman JA. The Lennox and Wolfe revised selfmonitoring scale: latent structure and gender invariance. Pers Individ Dif 2002;32:627-37.

67 Myszkowski N, Storme M, Zenasni F, et al. Appraising the duality of self-monitoring: psychometric qualities of the revised self-monitoring scale and the concern for appropriateness scale in French. Can J Behav Sci 2014;46:387-96.

68 Palese T, Schmid Mast M. The role of social categorization and social dominance orientation in behavioral adaptability. J Pers Soc Psychol 2020. doi:10.1037/pspi0000351. [Epub ahead of print: 30 Nov 2020].

69 Marques-Vidal P, Bochud M, Bastardot F. Assessing the associations between mental disorders, cardiovascular risk factors, and cardiovascular disease: the CoLaus/PsyColaus study. Raisons Santé 2011;182:1-28.

70 Radloff LS. The CES-D scale: a self-report depression scale for research in the general population. Appl Psychol Meas 1977;1:385-401.

71 Lewinsohn PM, Seeley JR, Roberts RE, et al. Center for epidemiologic studies depression scale (CES-D) as a screening instrument for depression among community-residing older adults. Psychol Aging 1997;12:277-87.

72 Beck AT, Ward CH, Mendelson M, et al. An inventory for measuring depression. Arch Gen Psychiatry 1961;4:561-71.

73 Beck AT, Steer RA, Carbin MG. Psychometric properties of the Beck depression inventory: twenty-five years of evaluation. Clin Psychol Rev 1988;8:77-100.

74 Troister T, D'Agata MT, Holden RR. Suicide risk screening: comparing the Beck depression Inventory-II, Beck Hopelessness scale, and Psychache scale in undergraduates. Psychol Assess 2015;27:1500-6.

75 Bourque P, Beaudette D. Étude psychometrique du questionnaire de dépression de Beck auprès d'un échantillon d'étudiants universitaires francophones. Can J Behav Sci 1982;14:211-8.

76 Spielberger CD. Manual for the State-trait anxiety inventory. Palo Alto, CA: Consulting Psychologists Press, 1983.

77 Spielberger CD. State-trait anxiety inventory: a comprehensive bibliography. 2nd ed. Palo Alto, CA: Consulting Psychologists Press, 1989.

78 Elliott TR, Shewchuk RM, Richards JS. Family caregiver social problem-solving abilities and adjustment during the inital year of the caregiving role. J Couns Psychol 2001;48:223-32.

79 Shewchuk RM, Richards JS, Elliott TR. Dynamic processes in health outcomes among caregivers of patients with spinal cord injuries. Health Psychol 1998;17:125-9.

80 Faye-Dumanget $\mathrm{C}$, Carré J, Le Borgne $\mathrm{M}$, et al. French validation of the Maslach burnout Inventory-Student survey (MBI-SS). J Eval Clin Pract 2017;23:1247-51.

81 Perrin M, Vandeleur CL, Castelao E, et al. Determinants of the development of post-traumatic stress disorder, in the general population. Soc Psychiatry Psychiatr Epidemiol 2014;49:447-57.

82 Humeniuk R, Ali R, Babor TF, et al. Validation of the alcohol, smoking and substance involvement screening test (assist). Addiction 2008;103:1039-47.

83 Deline S, Baggio S, Studer J, et al. Use of neuroenhancement drugs: prevalence, frequency and use expectations in Switzerland. Int $J$ Environ Res Public Health 2014;11:3032-45.

84 Berney A, Carrard V, Schmid Mast M, et al. Individual training at the undergraduate level to promote competence in breaking bad news in oncology. Psychooncology 2017;26:2232-7.

85 Carrard V, Bourquin C, Stiefel F, et al. Undergraduate training in breaking bad news: a continuation study exploring the patient perspective. Psychooncology 2020;29:398-405.

86 Berney A, Bourquin C. Individual supervision to enhance reflexivity and the practice of patient-centered care: experience at the undergraduate level. J Cancer Educ 2019;34:363-5.

87 Daeppen J-B, Fortini C, Bertholet N, et al. Training medical students to conduct motivational interviewing: a randomized controlled trial. Patient Educ Couns 2012;87:313-8.

88 Kane GC, Gotto JL, Mangione S, et al. Jefferson scale of patient's perceptions of physician empathy: preliminary psychometric data. Croat Med J 2007;48:81-6.

89 Laird NM, Ware JH. Random-effects models for longitudinal data. Biometrics 1982;38:963-74.

90 Schall R. Estimation in generalized linear models with random effects. Biometrika 1991;78:719-27.

91 van BS, Groothuis-Oudshoorn K. Mice: multivariate imputation by Chained equations in R. J Stat Softw 2010.

92 Brehm BJ, Summer SS, Khoury JC, et al. Health status and lifestyle habits of US medical students: a longitudinal study. Ann Med Health Sci Res 2016;6:341-7. 
93 Støen Grotmol K, Gude T, Moum T, et al. Risk factors at medical school for later severe depression: a 15-year longitudinal, nationwide study (NORDOC). J Affect Disord 2013;146:106-11.

94 Woloschuk W, Harasym PH, Temple W. Attitude change during medical school: a cohort study. Med Educ 2004;38:522-34.
95 Oser TK, Haidet P, Lewis PR, et al. Frequency and negative impact of medical student mistreatment based on specialty choice: a longitudinal study. Acad Med 2014;89:755-61.

96 Bexelius $\mathrm{T}$, Lachmann $\mathrm{H}$, Järnbert-Pettersson $\mathrm{H}$, et al. Stress among medical students during clinical courses: a longitudinal study using contextual activity sampling system. Int J Med Educ 2019;10:68-74. 